\title{
Relato de experiência: a produção de material LINFE no IFRJ
}

A report on an experiment: producing LINFE material at IFRJ

Elza Maria Duarte Alvarenga de Mello Ribeiro, Ms, IFRJ, elza.ribeiro@ifrj.edu.br

\section{Resumo}

Visando exemplificar o processo de criação de materiais LINFE no IFRJ, este artigo retoma sua história e descreve pontos básicos, como a análise de necessidades, diálogo entre disciplinas e consideração do desejo e das lacunas linguísticas dos discentes, fazendo-os [os materiais] relevantes e pertinentes ao contexto a que se destinam.

Palavras Chave: Material Linfe, análise das necessidades, produção de material.

\section{Abstract}

With the objective of exemplifying the process of creating LINFE materials, this article revisits its history and describes its main aspects, such as needs analysis, dialogue with other subjects, and consideration of students' linguistic gaps and their desires. Thus, the materials that are developed are relevant and pertinent to the context they are designed for.

Keywords: 'Linfe' Material, needs analysis, material design 


\section{Introdução}

O presente artigo traça o caminho através do qual os materiais foram e continuam sendo produzidos no IFRJ, desde os tempos da antiga nomenclatura da instituição Cefeteq, contemplando as atualizações dos cursos, alunos, conjuntura social-cultural de cada etapa até a contemporaneidade, bem como a evolução da fundamentação teórico-metodológica que rege nossas práticas do ensino de línguas no Instituto.

Não há juízo de valor entre uma etapa e outra, não há exclusão e/ou desconsideração de uma forma em detrimento da outra. Não existe, nesta perspectiva, bipolaridade de paradigmas entre os quais você nega um para aceitar outro. O movimento é justamente em outra direção, na busca pela complementaridade por uma forma cada vez mais eficaz e efetiva de desenvolver o trabalho com a qualidade que sempre o caracterizou no contexto educacional.

Para tal, apresenta-se, em linhas gerais, como se deu a evolução das práticas que caracterizavam o ensino de numa abordagem ainda denominada de Inglês Instrumental, passando pelo ESP (English for Specific Purposes, em Português, Inglês para Fins Específicos) até o que é denominado hoje de Linfe.

Seguir o trajeto acima descrito compromete-nos com escolhas e afiliações teóricas quanto à visão de linguagem e de ensino aprendizagem. Levar em consideração o ser na alteridade para construir a si, aos demais e ao contexto ao redor, influenciando e sendo influenciado pelo meio são algumas das questões cruciais para assumir o trabalho desta natureza.

O professor Linfe se caracteriza por ser um profissional comprometido com os múltiplos desafios a serem assumidos, dentre eles o de desempenhar múltiplos papéis no atendimento às demandas dos cursos e períodos em que atua, de forma que os aparatos teórico-metodológicos deem a ele sustentação ao trabalho de sala de aula.

Como consequência do acima exposto, o material Linfe é produzido e criado de forma a ser a concretização de práticas e teorias que dialogam entre si e tem como objetivo dar conta das possíveis variáveis que se apresentem no decorrer do processo como um todo.

\section{Breve histórico do Inglês Instrumental à nomenclatura Linfe no IFRJ}

O IFRJ, historicamente, é referência nacional para demais instituições na utilização do ensino Inglês Instrumental, como ainda era conhecido na época o ensino de língua inglesa, sendo citado em inúmeras publicações e replicado em escolas com objetivos afins, bem como sendo objeto de pesquisa, tanto no estudo das práticas em sala de aula, quanto na produção de material didático característico para fins específicos. 
Ao chegar ao Brasil, Inglês Instrumental passou a ser adotado como sendo o que melhor atendia as demandas e necessidades da instituição. Com o passar do tempo e necessidade de desvincular a prática apenas da noção do ensino da língua inglesa para leitura de textos técnicos, a nomenclatura para denominar a abordagem passou a ser ESP, como acima descrita.

Uma vez que outras línguas passam a fazer parte do quadro curricular do Instituto, novamente o nome passa a não dar conta da abordagem que também passa a atender o Espanhol, por exemplo. Assim sendo, na contemporaneidade, o que caracteriza o ensino-aprendizagem de Línguas no IFRJ passa a ser chamado de LINFE (Línguas para Fins específicos). Deste modo, observamos que houve não somente a troca de nomenclatura, mas também a mudança na abrangência da proposta, tornando imprescindível a renovação de ementas e materiais a serem usados em sala de aula. Ressalto que, apesar do termo usado incluir demais línguas, o artigo se detém a questões relacionadas ao ESP em função da própria formação das autoras que são professoras de língua inglesa na instituição.

\section{Visão de Linguagem e Processo Ensino Aprendizagem}

A concepção de linguagem que perpassa o trabalho aqui descrito é uma visão que dialoga com pressupostos balkhtinianos para quem o ser humano se constitui na alteridade e o indivíduo só se constrói na interação com os demais. A linguagem se configura como condição básica e mínima para nossa existência no mundo.

Como desdobramento dessa ideia, muito mais do que considerar a leitura como a mera decodificação de um conjunto de palavras, o texto passa a ser toda forma de comunicação de ideias e nesse sentido ele é infindável e inacabado, uma vez que alguns terminam e outros aparecem sócio-historicamente situados.

Nesta perspectiva, tudo passa a ser contexto para o texto que nos identifica por identidade própria. Somos contextos uns para os outros e tudo a nosso redor se torna contexto para os múltiplos textos que nos circundam. Assim, sendo os gêneros, em linhas gerais, passam a ser as formas como os textos se apresentam no mundo.

A partir disso, não há outra visão possível de se entender o processo de ensino aprendizagem sem aquela que contempla o sociointeracionismo de base Vygotskyana cujos conceitos são muito adequados como base para a educação, dentre eles: o par mais competente, a zona de desenvolvimento proximal, a consideração pelo conhecimento prévio do aluno, o entrelaçamento de vozes que se concretiza na alteridade do ambiente de sala de aula.

Juntando-se a isso, trago novamente Bakhtin (1929) para quem a sala de aula tem que ser polifônica, isto é, um contexto democrático onde todos têm voz e vez. Por esse motivo, ela, ao ser considerada polifônica, é ao mesmo tempo genuinamente heteroglóssica, ou seja, ao ouvir a voz do outro carregada de todas a histórias que o constituem e ao juntar essas vozes num novo texto de discussão e 
possibilidades, geramos um novo texto de natureza heteroglóssica, que jamais se repetirá em outro momento.

Por assim considerar todas as questões acima, conclui-se que toda e qualquer aula é única no universo. Jamais se configurará o mesmo contexto em nenhum outro momento da vida de cada um dos participantes do processo. Neste ponto é que reside a riqueza da educação, quando alicerçada em teorias que são vividas nas práticas de sala de aula e que a ratificam, ou não.

\section{0 professor Linfe}

Infelizmente, o professor Linfe é um termo quase que ignorado na academia e tampouco se tem a pretensão de defini-lo. Inúmeras são as razões para isso: (a) se considerarmos de onde vem sua formação, (b) para onde ele está sendo formado para desempenhar sua função, (c) como ele engendra todas as concepções supracitadas num contexto tão específico, dentre todas as outras variáveis que constituem o contexto local micro educacional em que está inserido. Portanto, concordo com Vian Jr (2015) que define esse profissional como um professor de inglês para fins gerais que se vê na iminência de atuar no contexto para fins específicos.

Em relação a esse tipo específico de formação docente (CELANI et al., 2005; RAMOS, 2009, CELANI, 2009; entre outros), a prática se mostra como carente de cursos de formação, atualização, especialização e/ou complementação dedicados a suprir essa necessidade. Há uma escassez de oferta de cursos dessa natureza, ainda mais se levarmos em consideração que o papel de um professor Linfe é bastante peculiar, pois na verdade ele deve estar capacitado para desempenhar uma variedade de papéis, para os quais não foi formado.

A situação acima exposta apresenta-se como um desafio, principalmente em tempos em que a demanda por profissionais qualificados para o mercado é premente e urgente.

\section{A produção de material LINFE a partir do referencial teórico- metodológico adotado}

Hutchinson and Waters (1987) foram os estudiosos precursores no desenvolvimento de uma abordagem de ensino que estivesse apoiada em três aspetos: análise de necessidades, desejo/vontade dos alunos e defasagem linguística dos mesmos. Abordagem essa que passou a ser denominada ESP (English for Specific Purposes, em Português, Inglês para Fins Específicos). Dentre os três fundamentos, há de se destacar que a análise das necessidades dos aprendizes assume o papel principal e o que a diferencia inovando a visão do processo ensino-aprendizagem das demais. Essa supremacia numa abordagem do ensino de línguas faz toda a diferença no tipo de trabalhado a ser desenvolvido em sala de aula, além de um tipo bem peculiar de planejamento e produção de material que venha a ser criado para atender as 
demandas. Segundo os autores, o fundamento do ensino está pautado na razão pela qual o aprendiz precisa aprender uma língua estrangeira. E, por essa razão, ele [o ensino] está diretamente relacionado com aprendizes, com a língua necessária e o com o contexto de aprendizagem.

São materiais que apresentam características muito peculiares, haja vista todo a fundamentação da qual os mesmos são frutos. Esse fato acontece para que a prática não fique defasada da teoria. Para tal, é imperioso que toda a estrutura que informa a prática seja examinada e reelaborada, especialmente após modificações institucionais de realocação das disciplinas em períodos diferentes da grade curricular anterior, em diálogo com consideração da nova conjuntura sócio-históricocultural em que a sala de aula está inserida.

A primeira das características que o definem tem a ver com a preocupação dos docentes da equipe de línguas em estar em diálogo constante com as outras equipes específicas e técnicas dos cursos nos períodos em que o inglês é oferecido.

Outro ponto que é válido de ser mencionado é a adequação das ementas e dos materiais didáticos para atender às sempre novas demandas das aulas de inglês nos cursos oferecidos pelo IFRJ. A constante revisão da análise das necessidades tem como consequência, de tempos em tempos, a renovação de ementas e a reelaboração de materiais didáticos mais atualizados, a fim de que se tornem adequados e pertinentes para a formação dos alunos.

Além disso, na atualidade, não só a leitura, mas também o ensino das habilidades (de compreensão escrita e oral e produção oral), se apresenta como fundamental nas aulas de LE nos cursos do IFRJ, uma vez que essa questão de comunicação em inglês é uma exigência da sociedade e do mercado de trabalho, que esperam dos nossos alunos o que de melhor eles podem oferecer no que diz respeito ao uso de línguas estrangeiras nas diversas funções em que exercerão nas suas profissões no futuro imediato.

A empreitada para dar conta de um material significativo que faça diferença na formação do aluno futuro técnico é de grande responsabilidade. É essencial a colaboração de todos os atores sociais envolvidos no processo: professores de inglês, professores das disciplinas do técnico e das exatas e alunos.

Desse modo, garantimos que os materiais produzidos sejam reflexo do aprofundamento teórico precedente e sejam co-construídos, dando voz e vez aos participantes dessa prática social, visando fazer as aulas de inglês do IFRJ mais proveitosas, relevantes e eficientes.

Somente com a conscientização e participação dos discentes na atualização de materiais a serem produzidos é que eles passam a dar credibilidade à disciplina, ao mesmo tempo em que percebem a relevância dos conteúdos aprendidos na sua formação.

Finalizando, são materiais altamente qualificados que triangularam conteúdos técnicos, a voz dos alunos e as demandas do mercado, a fim de ampará-los com o 
aparato linguístico necessário para o sucesso num futuro tanto a curto, quanto a médio e longo prazos. É importante que os alunos que desfrutam de uma formação integral de qualidade, tenham a chance de ter 0 aprendizado das línguas estrangeiras com mesmo nível de excelência. É importante para todos: professores estarão sempre num movimento de atualização; materiais sempre sofrendo atualizações; práticas em constante renovação e a instituição continuará como referência de ponta na abordagem em questão.

\section{Referências Bibliográficas}

BAKHTIN, M.; VOLOCHINOV, V.N. Marxismo e filosofia da linguagem (1929). Trad. Michel Lahud; Yara Frateschi Vieira. 7. ed. São Paulo: Hucitec, 1995.

CELANI, M. A. A.; DEYES, A. F.; HOLMES, J. L.; SCOTT, M. R. ESP in Brazil: 25 years of reflection and evolution. Campinas: Mercado de Letras, 2005.

CELANI, M.A.A. English for Specific Purposes: When myth and reality meet: reflections on ESP in Brazil. v. 27, p. 412 - 423. São Paulo: Mercado de Letras, 2009.

HUTCHINSON, T., \& WATERS, A. English for specific purposes: A learningcentered approach. Cambridge: Cambridge University Press, 1987

RAMOS, R. C. G. A história da abordagem instrumental na PUCSP. In: CELANI, M.A.A.; FREIRE, M.M.; RAMOS, R. de C. G. (Org.). A Abordagem instrumental no Brasil: Um projeto, seus percursos e seus desdobramentos. 01ed.Campinas, SP: Mercado de Letras, 2009, v. 01, p. 35-46.

VIAN JR., O. A formação inicial do professor de inglês para fins específicos. In: Perspectivas em línguas para fins específicos: Festschrift para Rosinda Ramos. p. 187-208. Campinas: Pontes Editores, 2015. 